\title{
Polyethylene glycol density and length affects nanoparticle uptake by cancer cells
}

\begin{abstract}
The prospective cancer therapy applications of inorganic nanoparticles (NPs) have been encouraged by surface modifications with polyethylene glycol (PEG). When grafted at high densities, PEG reduces NP surface interaction with its environment, hence minimizing its detection by the immune system. The drawback of high density PEG surfaces is its reduced uptake by cancer cells. This is disadvantageous for applications that favor intracellular localization of such NPs. On the other hand, reduced PEG density leads to nonspecific adsorption of proteins on NP surface. Adsorbed proteins may either facilitate cancer cell entry or mark inorganic NPs for clearance from the body. This trade-off between intracellular localization and in vivo residency time was observed in this study. Two grafting densities of $1 \mathrm{PEG} / \mathrm{nm}^{2}$ and $1 \mathrm{PEG} / 2 \mathrm{~nm}^{2}$ for two PEG chain lengths with molecular weights of $2 \mathrm{kDa}$ and $5 \mathrm{kDa}$ were used to coat gold NPs (GNPs). Spherical GNPs with a diameter of $50 \mathrm{~nm}$ were used as a model system to investigate the effect of PEG characteristics on NP nonspecific protein adsorption and uptake by cancer cells in vitro in HeLa, MDAMB-231 and MCF-7 cells. Higher grafting densities resulted into less protein adsorption and lower NP uptake by all cell lines. Longer PEG chain lengths also resulted into less cancer cell entry in all cell lines. Quantitative results were confirmed qualitatively via hyperspectral imaging of NPs in cancer cells. Hence, lower PEG grafting densities and shorter chain lengths lead to higher cellular uptake at the cost of greater nonspecific protein adsorption. Higher density grafting of shorter PEG chain lengths was found most favorable. This combination resulted into reduced nonspecific protein adsorption and higher uptake when compared to its lower density and longer chain length counterparts, respectively. To maximize cancer therapy improvement via inorganic NP platforms, using such PEG grafting characteristics may be beneficial.
\end{abstract}

Keywords: Nanotechnology, Nanoparticles, Gold, Polyethylene glycol, Cellular uptake, Hyperspectral imaging
Volume I Issue I - 2014

\author{
Charmainne Cruje,' Devika B Chithrani',2 \\ 'Department of Physics, Ryerson University, Canada \\ 2Li KaShing Knowledge Institute, St. Michael's Hospital, Canada
}

Correspondence: Devika B. Chithrani, Department of Physics, Ryerson University, 350 Victoria Street, Toronto, Ontario, Canada ,Tel 4I6-979-5000 ext. 4II5, Email devika.chithrani@ryerson.ca

Received: August 10,2014 | Published: October 18, 2014
Abbreviations: NP, Nanoparticle; GNP, Gold NP; PEG, Polyethylene Glycol; PEG-GNP, PEG-coated GNP; EPR, Enhanced Permeability and Retention; RME, Receptor Mediated Endocytosis; HP2K-GNP, 1 PEG/nm² 2kDa PEG; LP2K-GNP, 1 PEG/2nm² 2kDa PEG; HP5K-GNP, 1 PEG/nm ${ }^{2}$ 5kDa PEG; LP5K-GNP: 1 PEG/2nm² 5kDa PEG; UV-Vis: Ultraviolet-Visible Spectroscopy; DLS: Dynamic Light Scattering; PBS: Phosphate-Buffered Saline; HSI: Hyperspectral imaging; SAM: Spectral Angle Mapping; ICPAES: Inductively Coupled Plasma Atomic Emission Spectroscopy

\section{Introduction}

The biomedical research of inorganic nanoparticles (NPs) has developed NP-based cancer therapeutics and imaging. ${ }^{1-7}$ Through such applications, disease may be managed safely and more efficiently.,2,8-11 Though not yet clinical, NP platforms are being developed to target therapeutics to tumors while minimizing interaction with normal tissue. ${ }^{12-14}$ To achieve an efficient NP system, prolonged in vivo residency time, preferential localization in tumor environments and cancer cell internalization for applications that favor intracellular localization is required. ${ }^{15,16}$ The first requirement of longer blood circulation time is most important because NPs should not be cleared from the body before its interaction with tumor tissue. To achieve favorable blood circulation times and cancer cell targeting, various NP sizes, shapes and surfaces have been studied. ${ }^{17-20}$ For example, gold NPs (GNPs) whose surface was modified with folic acid was found to target cancer cells versus healthy cells as it was found to deliver doxorubicin more effectively to HeLa cells in comparison to MDCK cells. ${ }^{21}$ Similarly, magnetic iron oxide NPs that targeted urokinase plasminogen activator receptors were found effective for drug delivery and imaging of cells that over expressed such receptors. ${ }^{22,23}$ However, prior to cancer cell targeting, long blood circulation times must be achieved so that NPs may enter tumor tissue to begin with. This is achieved by surface modification of NPs with polyethylene glycol (PEG) or PEGylation, as found in numerous in vivo studies. ${ }^{11,15,16,18,19,24-28}$

PEG is widely used in providing NPs with stealth properties, hence prolonging blood circulation times. ${ }^{26,27}$ For example, Lipka et al showed that a longer PEG chain length of $10 \mathrm{kDa}$ improved NP blood circulation time as over $15 \%$ of applied volume was found after 24 hours in the bloodstream of mice subjects. ${ }^{27}$ On the other hand, its unmodified counterpart was cleared within an hour of intravenous application. Likewise, Cho et al found that PEG-coated NPs accumulate in immune system organs responsible for NP body clearance for more than six months. ${ }^{18}$ The molecule accomplishes this by surrounding NPs with a hydrophilic layer, protecting the NP surface from the environment. ${ }^{15,18,25,27,29,30}$ High density grafting of polymers allow such molecules to assume what is referred to as a brush conformation as opposed to a mushroom configuration at low density (31,32). In addition to grafting density, conformations are determined by polymer chain length $(n)$, monomer length $(\alpha)$, and solvent type $(v)$ as shown in equation (1)..$^{31-33}$

$$
\mathrm{R}=\alpha n^{v}
$$

Here, $\mathrm{R}$ is the Flory radius, which defines the minimum distance required between grafted molecules to achieve a mushroom 
conformation. Molecules spaced less than $\mathrm{R}$ have lower conformational freedom such that a brush conformation is achieved. For example, $\mathrm{PEG}$, whose monomer length is $0.35 \mathrm{~nm}$, with a molecular weight of $2 \mathrm{kDa}$ (polymer chain length of 45.45$)$ in water $(v=3 / 5), \mathrm{R}$ is 3.5 $\mathrm{nm}$, while for a molecular weight of $5 \mathrm{kDa}$, it is $6.0 \mathrm{~nm}$. For a $50 \mathrm{~nm}$ spherical NP of surface area $7854 \mathrm{~nm}^{2}$, if $2 \mathrm{kDa}$ molecules were to take on a brush configuration grafted a maximum of $3.5 \mathrm{~nm}$ apart (1 PEG molecule per $(3.5 \mathrm{~nm})^{2}$ or $\left.12.25 \mathrm{~nm}^{2}\right)$, at least 641 molecules are required per NP. Likewise, $5 \mathrm{kDa}$ molecules require $1 \mathrm{PEG}$ molecule per $36 \mathrm{~nm}^{2}$ or 218 molecules per NP. However, it was found that a minimum density of $1 \mathrm{PEG} / \mathrm{nm}^{2}$ is required to achieve a significant reduction in nonspecific protein adsorption. ${ }^{30,34}$ One of such proteins that the NP surface is protected from is opsonin. ${ }^{26,30,34,35}$ Opsonin marks NPs for macrophage detection followed by their clearance from the body. With PEGylation, NPs may evade the immune system, achieving longer blood circulation times. This in turn allows higher chances of NP entry and retention in tumor tissue, since such an environment has leaky capillaries and irregular lymphatic structures leading to the enhanced permeability and retention (EPR) effect. ${ }^{16,36}$ The EPR effect is taken advantage of by PEGylated liposomes used in chemotherapy, since it allows preferential accumulation of NPs in the tumor. PEGylated liposomes sized 100-200 nm are currently used as delivery vehicles for FDA-approved chemotherapeutic drugs like doxorubicin and oncospar. ${ }^{3,37}$ It was the effectiveness of PEG in this respect that motivated the study of other biocompatible NPs, such as GNPs.

The use of inorganic NPs is of interest as they are easily synthesized and designed, especially in the case of GNPs whose physical and chemical properties are easily modifiable..$^{24,38,39}$ For example, the citrate reduction method of synthesis more popularly known as the Turkevich method only requires varying concentrations of sodium citrate to vary GNP size. Surface modification may also be done with ease via electrostatic attraction, chemisorption, and displacement of surface bound ligands..$^{24}$ However, unlike liposomes and as with other inorganic NPs, GNPs need surface ligands for cellular internalization, since inorganic NPs enter cells by receptor mediated endocytosis (RME). ${ }^{1,2}$ Citrate-coated GNPs synthesized from the Turkevich method accomplish this by nonspecific adsorption of proteins in serum, which is minimized by PEG. Because of this, PEGylated GNPs are found to have decreased cellular uptake in vitro. ${ }^{40-43}$ Nativo et al found that PEGylated GNPs had significantly less uptake by HeLa cells. Similarly, Arnida et al found the same trend using PC-3 cells. ${ }^{35}$ This suggests that when doing in vivo studies, PEGylated GNPs localize external to cancer cells in interstitial tissue. Chemotherapeutic toxicity relies on the entry of drugs into cancer cells. ${ }^{42,44} \mathrm{NP}$ cellular uptake was also found to correlate with sensitization of cancer cells to radiation therapy. ${ }^{45-48}$ It may be considered favorable to minimize the volume of unused inorganic NPs in the body because such particles accumulate in immune system organs, causing side effects that include kidney and liver failure ${ }^{17,18,25,27} \mathrm{~A}$ balance between cancer cell uptake and $\mathrm{NP}$ stealth from the immune system by avoiding nonspecific protein adsorption is required.

The trade-off between cellular internalization and nonspecific protein adsorption was observed in this study by varying PEG grafting characteristics on NPs, where GNPs were used as a model system (Figure 1). Grafting densities of $1 \mathrm{PEG} / \mathrm{nm}^{2}$ and $1 \mathrm{PEG} / 2 \mathrm{~nm}^{2}$ for two PEG chain lengths of molecular weights $2 \mathrm{kDa}$ and $5 \mathrm{kDa}$ were used to coat GNPs. In all cases, sufficient PEG molecules were grafted to achieve a brush conformation of molecules. Spherical GNPs with a diameter of $50 \mathrm{~nm}$ were used to investigate the effect of PEG grafting characteristics on nonspecific protein adsorption and cellular uptake in vitro in HeLa, MDA-MB-231 and MCF-7 cells. Quantitative results were also confirmed qualitatively by Hyperspectral Imaging (HSI) of NPs in cancer cells using Cyto Viva. The results of this study may be used as a guideline in designing inorganic NPs with prolonged blood circulation time and sufficient cancer cell uptake for potential clinical use.

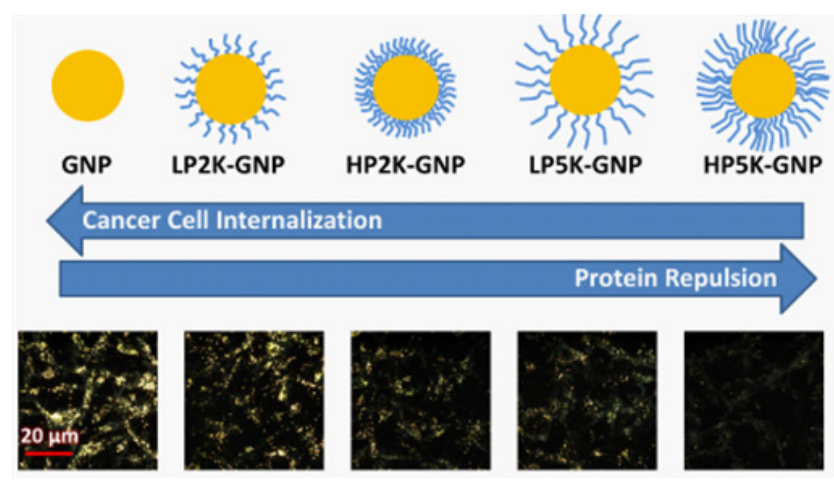

Figure I Schematic on the effect of PEG characteristics on cancer cell uptake of NPs. Two grafting densities and two chain lengths were studied. Lower grafting densities and shorter PEG chain lengths resulted into higher nonspecific protein adsorption. This in turn led to greater NP internalization by cancer cells. Quantified cellular uptake was also evaluated qualitatively by dark field microscopy, where there was a general agreement between quantified data and observed fluorescence.

\section{Materials and methods}

GNP synthesis: GNPs were synthesized via the citrate reduction method. $600 \mu \mathrm{L}$ of $1 \%$ Chloroauric acid (Sigma-Aldrich, Oakville, $\mathrm{ON}$ ) was added to $60 \mathrm{~mL}$ of distilled water and was brought to a boil while continuously stirring. At boiling point, $210 \mu \mathrm{L}$ of $1 \%$ citric acid (Sigma-Aldrich, Oakville, ON) was added to synthesize mediumsized GNPs. The color of the solution changed from clear to black, then to maroon. The solution was left to boil for another five minutes while stirring. It was then allowed to cool to room temperature while stirring followed by refrigeration.

Characterization and nonspecific protein adsorption: GNPs were characterized with ultraviolet-visible (UV-vis) spectroscopy (Lambda 40; PerkinElmer, Waltham, MA) and dynamic light scattering (DLS) using the 90 Plus Particle Size Analyzer (Brookhaven Instruments Corp., New York, NY; Figure 2 and Table 1). To assess serum protein adsorption, peak absorption and diameter characterization was also done for all NPs following their incubation with Fetal Bovine Serum (FBS; Sigma-Aldrich, Oakville, ON). This was done under the same concentrations as the cellular uptake study described in the cellular uptake study. Dark field imaging of synthesized GNPs was also done with CytoViva HSI (Cytoviva Inc., Auburn, AL). To establish reference spectra for use in matching GNPs internalized by cells, spectral information on synthesized GNPs were collected (Figure 2).

PEGylation of GNPs: A 1\% PEG solution was prepared with thiolterminated PEG methyl ether (Polymer Source Inc., Dorval, QC) for each polymer molecular weight of $2 \mathrm{kDa}$ and $5 \mathrm{kDa}$. The solution was added to GNPs to achieve a surface grafting density of $1 \mathrm{PEG} / \mathrm{nm}^{2}$ or $1 \mathrm{PEG} / 2 \mathrm{~nm}^{2}$. From UV-Vis results, the peak absorption wavelength of $535 \mathrm{~nm}$ corresponds to a diameter of $50 \mathrm{~nm}$. Hence, 7854 PEG molecules were required per GNP to achieve a density of 1 PEG/ $\mathrm{nm}^{2}$, synthesizing HP2K-GNP with 2kDa PEG and HP5K-GNP with 5kDa PEG. On the other hand, 3927 PEG molecules were required to achieve a density of $1 \mathrm{PEG} / 2 \mathrm{~nm}^{2}$, synthesizing LP2K-GNP with $2 \mathrm{kDa}$ PEG and LP5K-GNP with 5kDa PEG. To confirm the PEGylation of 
GNPs, DLS and UV-Vis measurements were done since an increase in diameter is characteristic of GNP PEGylation (Table 1).

Table I Characterization of NPs before and after incubation with serum via UV-Vis and DLS.After incubation, a greater increase in hydrodynamic diameter was observed with shorter PEG chain lengths and lower grafting densities

\begin{tabular}{|c|c|c|c|c|}
\hline \multirow[b]{2}{*}{$\begin{array}{l}\text { NP } \\
\text { Type }\end{array}$} & \multicolumn{2}{|c|}{ Pre-Incubation } & \multicolumn{2}{|c|}{ Post-Incubation } \\
\hline & $\begin{array}{l}\text { UV-Vis } \\
\text { Peak } \\
\text { Wavelength } \\
(\mathrm{nm})\end{array}$ & $\begin{array}{l}\text { Hydro } \\
\text { dynamic } \\
\text { Diameter } \\
(\mathrm{nm})\end{array}$ & $\begin{array}{l}\text { UV-Vis Peak } \\
\text { Wavelength } \\
(\mathrm{nm})\end{array}$ & $\begin{array}{l}\text { Hydrodynamic } \\
\text { Diameter }(\mathrm{nm})\end{array}$ \\
\hline GNP & 535 & $\begin{array}{l}53.6 \pm 0.5 \\
\mathrm{~nm}\end{array}$ & 539 & $66.9 . \pm 0.4 \mathrm{~nm}$ \\
\hline $\begin{array}{l}\text { HP2K- } \\
\text { GNP }\end{array}$ & 536 & $\begin{array}{l}55.2 \pm 0.2 \\
\mathrm{~nm}\end{array}$ & 538 & $58.3 \pm 0.5 \mathrm{~nm}$ \\
\hline $\begin{array}{l}\text { LP2K- } \\
\text { GNP }\end{array}$ & 535 & $\begin{array}{l}54.7 \pm 0.3 \\
\mathrm{~nm}\end{array}$ & 542 & $61.7 \pm 0.6 \mathrm{~nm}$ \\
\hline $\begin{array}{l}\text { HP5K- } \\
\text { GNP }\end{array}$ & 537 & $\begin{array}{l}64.1 \pm 0.3 \\
\mathrm{~nm}\end{array}$ & 540 & $65.6 \pm 0.2 \mathrm{~nm}$ \\
\hline $\begin{array}{l}\text { LP5K- } \\
\text { GNP }\end{array}$ & 536 & $\begin{array}{l}62.0 \pm 0.3 \\
\mathrm{~nm}\end{array}$ & 540 & $63.6 \pm 0.5 \mathrm{~nm}$ \\
\hline
\end{tabular}

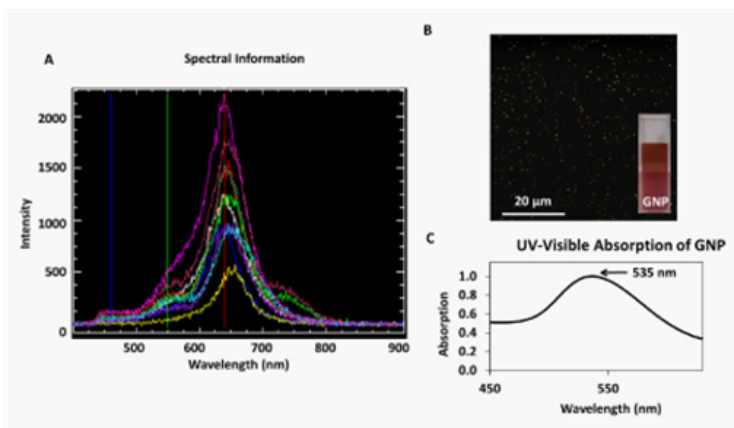

Figure 2 Characterization of GNP solution.

A) Sample GNP spectra of varying intensities collected via HSI of

B) GNP taken with CytoViva.

Cellular uptake study: HeLa, MDA-MB-231 and MCF-7 cells were cultured in Dulbecco's Modified Eagle's Medium (Life Technologies Inc., Burlington, ON) with 10\% FBS. Cells were grown to confluency so that per NP type per cell line, there were two $10-\mathrm{cm}$ culture dishes. For optical imaging purposes, MDA-MB-231 cells were seeded on glass cover slips in 3.5-cm culture dishes and grown to confluency. All NP types were added to cell cultures to achieve a concentration of 2.0 $\times 1013 \mathrm{GNPs} / \mathrm{L}$ for a 16 -hour incubation period at $37^{\circ} \mathrm{C}$ and $5 \% \mathrm{CO} 2$. Phosphate-Buffered Saline (PBS; Sigma-Aldrich, Oakville, ON) was used to wash all cell cultures three times. The $10-\mathrm{cm}$ culture dishes without cover slips were trypsinized for quantification described in the NP uptake quantification. The $3.5-\mathrm{cm}$ culture dishes with cover slips were fixed with 4\% paraformaldehyde (Sigma-Aldrich, Oakville, $\mathrm{ON}$ ) in PBS for 20 minutes at room temperature, and then washed with PBS. Coverslips were mounted onto glass slides for CytoViva microscopy as described in the microscopy.

NP uptake quantification: Prior to processing for inductively coupled plasma atomic emission spectroscopy (ICP-AES) with the Optima 7300 DV (PerkinElmer, Waltham, MA), trypsinized cells were counted. To prepare samples for ICP-AES, $70 \%$ nitric acid (Sigma-Aldrich, Oakville, ON) was added at the same volume as the samples. Samples were boiled at $200^{\circ} \mathrm{C}$ in an oil bath for cell digestion and GNP atomization. ICP-AES of the samples was then performed yielding gold atom counts that were converted to internalized NPs per cell (Figures 3 and 4).

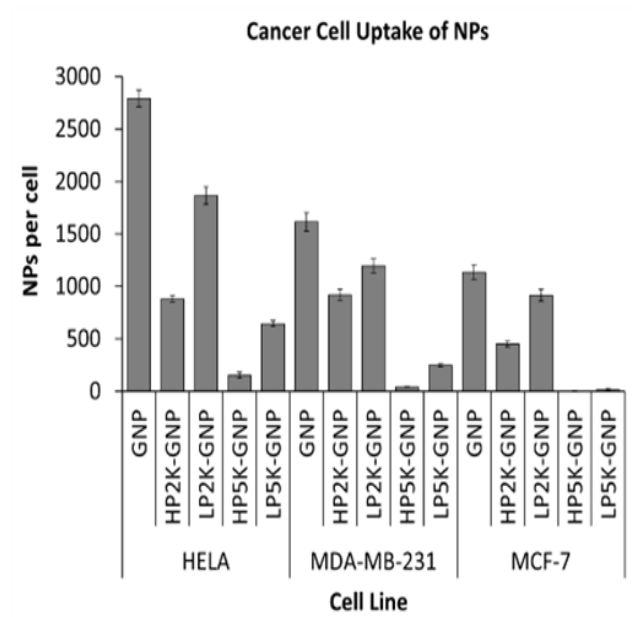

Figure 3 The dependence of NP uptake on cell line. Highest uptake was observed in HeLa cells for all NP types followed by uptake by MDA-MB-23I cells, then MCF-7 cells.

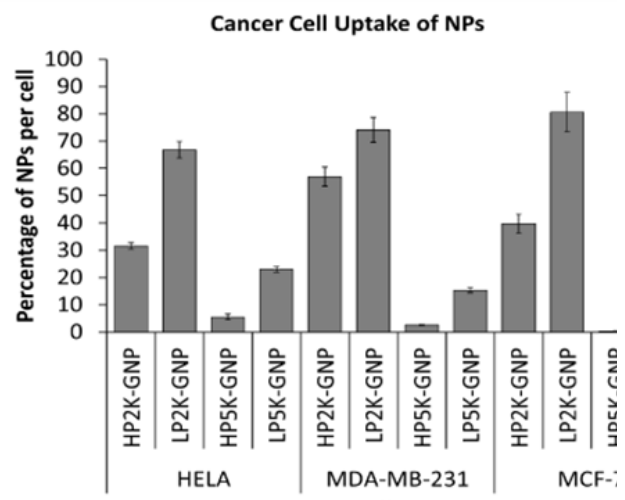

Figure 4 The dependence of cancer cell uptake on PEG characteristics. Cellular internalization of PEG-GNPs were normalized to that of as-made GNPs. Higher uptake was observed with shorter PEG chain lengths and lower densities for all cell lines.

CytoViva microscopy of internalized NPs: As a qualitative evaluation of cellular uptake, CytoViva microscopy of cells incubated with NPs was done (Figure 5 and 6). This imaging system was designed so that despite NP interaction with cells or tissue, their spectra may be confirmed because they are still optically visible. The dark-field imaging system developed by CytoViva uses oblique angle lighting, which results into high signal-to-noise images. With the use of the spectral angle mapping (SAM) feature of CytoViva, unknown spectra from HSI of MDA-MB-231 cells incubated with NPs were compared to collected reference spectra as shown in (Figure 2). Spectra of samples internalized by MDA-MB-231 cells were matched with a maximum angle of 0.2 radians (Figure 5). This was done to confirm that fluorescent particles were indeed GNPs.

\section{Results and Discussion}

Characterization of synthesized NPs: Spherical GNPs with a diameter of $50 \mathrm{~nm}$ were made as characterized by its peak absorption wavelength of $535 \mathrm{~nm}$ with UV-Vis (Table 1 and Figure 2). The PEGylation of GNPs resulted into shifts in peak absorption, which is characteristic of molecule adsorption on NP surfaces. A maximum change in peak absorption wavelength of $2 \mathrm{~nm}$ was observed with PEGylation, which did not signify the aggregation of NPs, confirming its stability. DLS measurements also confirmed NP PEGylation and 
stability. A hydrodynamic diameter increase of $1.6 \pm 0.5 \mathrm{~nm}$ was observed with HP2K PEGylation while an increase of $1.1 \pm 0.6 \mathrm{~nm}$ was observed with LP2K PEGylation. It appears that a lower grafting density provides more free space for PEG molecules to take less erect conformations versus its high density counterpart. For the longer PEG chain length of $5 \mathrm{kDa}$, a hydrodynamic diameter increase of $10.5 \pm 0.6$ and $8.4 \pm 0.6 \mathrm{~nm}$ was observed with HP5K and LP5K PEGylation, respectively. In comparison to the shorter PEG chain length of $2 \mathrm{kDa}$, larger hydrodynamic diameter changes were observed for $5 \mathrm{kDa}$ as expected.
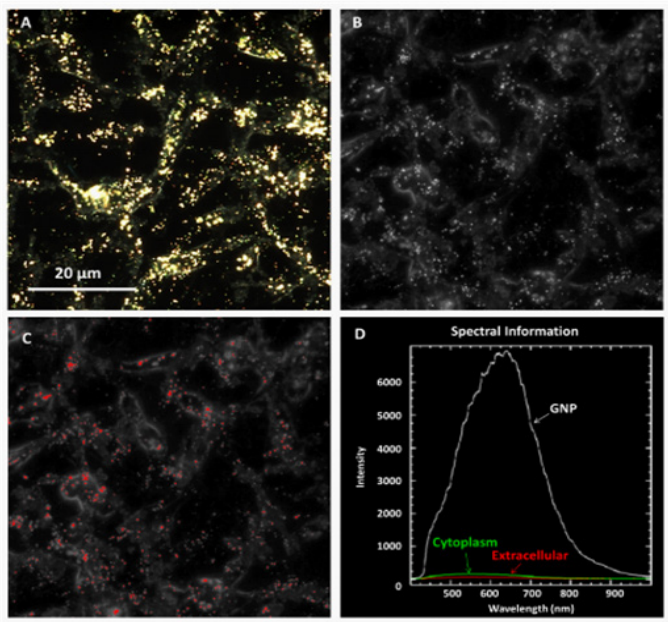

Figure 5 Spectra matching in HSI image at 60X.

A) MDA-MB-23I cells incubated with GNPs were imaged.

B) HSI was done.

C) Using obtained spectra from synthesized GNPs, pixels whose spectra matched reference spectra were identified and marked in red.

D) Intensity differences between the GNP, cytoplasm and extracellular regions display that observed bright particles were indeed GNPs.

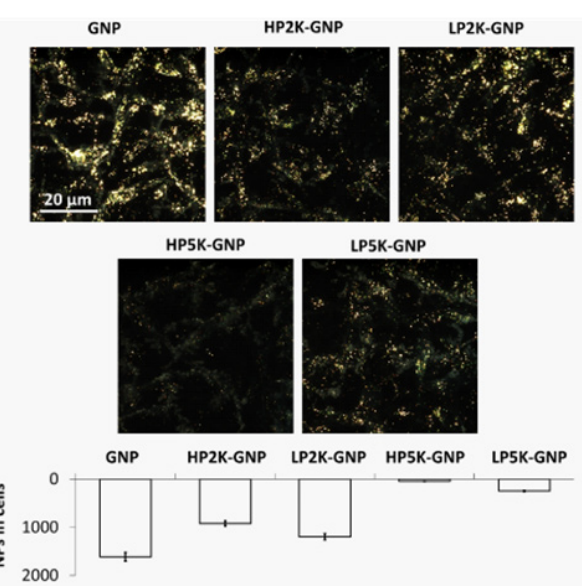

Figure 6 NPs in MDA-MB-23I cells and corresponding quantification data. There is general agreement between the observed number of fluorescent particles and measured gold concentration.

Nonspecific protein adsorption: The incubation of NPs with serum resulted into larger hydrodynamic diameters due to nonspecific protein adsorption (Table 1). The largest increase of $13.3 \pm 0.6 \mathrm{~nm}$ was observed for as-made GNPs due to the absence of PEG molecules that repel nonspecific protein adsorption. Following this, diameters increased by $3.1 \pm 0.5$ and $7.0 \pm 0.7$ for HP2K-GNPs and LP2K-GNPs respectively. Due to lower PEG grafting density and the availability of free space on NP surface, there was a higher chance of serum protein binding for LP2K-GNPs in comparison to HP2K-GNPs. On the other hand, HP5K-GNPs and LP5K-GNPs increased in diameter by $0.9 \pm$ 0.4 and $1.6 \pm 0.6 \mathrm{~nm}$ respectively. The longer PEG chain length was able to more effectively hinder protein interaction with NP surface.

Quantifying internalization of NPs by cancer cells: Highest NP uptake was observed in HeLa cells across all NP types (Figure 3). Following this was the NP uptake by MDA-MB-231 cells, then MCF7 cells. Despite differences in the amount o

f NP uptake, the same trend was observed for all cell lines in terms of PEG characteristics. The cellular uptakes of PEG-GNPs in comparison to their as-made counterparts are shown in (Figure 4). A lower grafting density was found to have higher uptake for both PEG chain lengths. In addition, shorter PEG chain lengths resulted into higher uptake for both grafting densities. The reason for such observations is as explained above in the nonspecific protein adsorption results. Nonspecific protein adsorption was found to increase with shorter PEG chain lengths and lower grafting densities. Since protein adsorption mediates the entry of inorganic NPs by RME, the chances of PEG-GNPs entering cells correlate with the amount of protein on its surface. Hence, cancer cell uptake was also found to increase with shorter PEG chain lengths and lower grafting densities.

Imaging of NPs in cancer cells: Spectral information of as-made GNPs with varying intensities was collected as seen in (Figure 2). Varying intensities may have been caused by differences in distance so that NPs closer to the objective in the viewing plane had higher intensities than those farther from it. Using collected spectra from as-made GNP solutions as shown in (Figure 2), matches in MDAMB-231 cells were imaged with SAM and it was confirmed that fluorescent particles were indeed GNPs (Figure 5). Observed fluorescence in acquired images of NPs in cells was found to generally agree with gold quantifications (Figure 6). An increase in the number of fluorescent particles was found to increase with uptake.

\section{Conclusion}

This study demonstrated the trade-off between PEG grafting density for minimized nonspecific protein adsorption and cancer cell uptake of inorganic NPs. Lower PEG grafting densities and shorter chain lengths have higher cancer cell uptake due to a greater probability of nonspecific protein adsorption. However, this also means that immune system markers such as the opsonin protein also have a higher chance of binding with such NPs, promoting clearance from the body. Based on results, a PEG chain length of $2 \mathrm{kDa}$ grafted at $1 \mathrm{PEG} / \mathrm{nm}^{2}$ repels protein adsorption sufficiently without reducing uptake as much as $5 \mathrm{kDa}$ PEG does. In addition, minimized nonspecific protein adsorption by $5 \mathrm{kDa}$ may be found problematic when dealing with body clearance of NPs. Results from this study show that the nonspecific protein adsorption properties of such conjugates require a time point study. Such will establish the time it takes for longer PEG chain lengths to adsorb the same amount of protein as shorter PEG chain lengths. This may then be associated with in vivo residency time of PEGylated NPs. In the event that such uptake is inadequate in enhancing cancer treatment outcomes, the use of cancer cell targeting ligands may be used. The integration of targeting ligands will provide NPs with both longer residency times and enhanced internalization by cells. Such properties will promote the clinical use of prospective inorganic NP platforms.

\section{Acknowledgments}

None. 


\section{Conflict of interest}

None.

\section{References}

1. Chithrani DB Intracellular uptake, transport, and processing of gold nanostructures. Mol Membr Biol. 2010;27(7):299-311.

2. Chithrani DB Optimization of Bio-Nano Interface Using Gold Nanostructures as a Model Nanoparticle System. Insciences J 2011;1(3):136-156.

3. Chithrani DB Nanoparticles for Improved therapeutics and Imaging in Cancer Therapy. Recent Pat Nanotechnol. 2010;4(3):171-180.

4. Jelveh S, Chithrani DB Gold Nanostructures as a Platform for Combinational Therapy in Future Cancer Therapeutics. Cancers (Basel). 2011;3(1):1081-1110.

5. Singh R, Nalwa HS Medical applications of nanoparticles in biological imaging, cell labeling, antimicrobial agents, and anticancer nanodrugs. $J$ Biomed Nanotechnol. 2011;7(4):489-503.

6. Ravi Kumar MNV, Sameti M, Kneuer C et al. Polymeric nanoparticles for drug and gene delivery. In: Nalwa HS (Ed.), Encyclopedia of Nanoscience and Nanotechnology, Volume 9, American Scientific Publishers, Los Angeles, CA, p. 2004;1-19.

7. Nakache E, Poulain N, Candau F et al. Biopolymer and polymer nanoparticles and their biomedical applications. In: Nalwa $\mathrm{H}(\mathrm{Ed})$ Handbook of nanostructured materials and nanotechnology, (1st edn), Academic Press, San Diego, CA 5: pp. 2000;577-635.

8. Cuenca AG, Jiang $\mathrm{H}$, Hochwald $\mathrm{SN}$ et al. Emerging implications of nanotechnology on cancer diagnostics and therapeutics. Cancer. 2006;107(3):459-466.

9. Hauck TS, Jennings JL, Yatsenko $T$ et al. Enhancing the toxicity of cancer chemotherapeutics with gold nanorod hyperthermia. Adv Mater. 2008;20:3832-3838.

10. Rao J Shedding light on tumors using nanoparticles. ACS Nano. 2008;2(10):1984-1986.

11. Zhan T, Li P, Bi S et al. 12P-conjugated PEG-modified gold nanorods combined with near-infrared laser for tumor targeting and photothermal therapy. J Nanosci Nanotechnol. 2012;12(9):7198-7205.

12. Alivisatos $\mathrm{P}$ The use of nanocrystals in biological detection. Nat Biotechnol. 2003;22(1):47-51

13. Liong $\mathrm{M}, \mathrm{Lu} \mathrm{J}$, Kovochich $\mathrm{M}$ et al. Multifunctional inorganic nanoparticles for imaging, targeting, and drug delivery. ACS Nano. 2008;2(5):889-896.

14. Perrault SD, Walkey $\mathrm{C}$, Jennings $\mathrm{T}$ et al. Mediating tumor targeting efficiency of nanoparticles through design. Nano Lett. 2009;9(5):19091915.

15. Ding Y, Zhou YY, Chen $\mathrm{H}$ et al. The performance of thiol-terminated PEG-paclitaxel-conjugated gold nanoparticles. Biomaterials. 2013;34(38):10217-10227.

16. Li SD, Huang L Stealth nanoparticles: high density but sheddable PEG is a key for tumor targeting. J Control Release. 2010;145(3):178-181.

17. Zhang XD, Wu D, Shen X et al. Size-dependent in vivo toxicity of PEGcoated gold nanoparticles. Int J Nanomedicine. 2011;6:2071-2081.

18. Cho WS, Cho M, Jeong J et al. Size-dependent tissue kinetics of PEGcoated gold nanoparticles. Toxicol Appl Pharmacol. 2010;245(1):116123.

19. Maldiney T, Richard C, Seguin J et al. Effect of core diameter, surface coating, and PEG chain length on the biodistribution of persistent luminescence nanoparticles in mice. ACS Nano. 2011;5(2):854-862.
20. Akiyama Y, Mori T, Katayama Y et al. The effects of PEG grafting level and injection dose on gold nanorod biodistribution in the tumor-bearing mice. J Control Release. 2009;139(1):81-84.

21. Dharmatti R, Phadke C, Mewada A et al. Surface orchestration of gold nanoparticles using cysteamine as linker and folate as navigating molecule for synaphic delivery of doxorubicin. Journal of Nanomedicine Research. 2014;1(1):00002.

22. Malekigorji M, Curtis ADM, Hoskins $\mathrm{C}$ Use of iron oxide nanoparticles for pancreatic cancer therapy. Journal of Nanomedicine Research 2014;1(1):12.

23. Lee GY, Qian WP, Wang L et al. Theranostic nanoparticles with controlled release of gemcitabine for targeted therapy and MRI of pancreatic cancer. ACS Nano. 2013;7(3):2078-2089.

24. D Yohan, Chithrani DB Applications of nanoparticles in nanomedicine J Biomed Nanotechnol. 2014;10:2371-2392.

25. Cho WS, Cho M, Jeong J et al. Acute toxicity and pharmacokinetics of 13 nm-sized PEG-coated gold nanoparticles. Toxicol Appl Pharmacol. 2009;236(1):16-24.

26. Khlebtsov N, Dykman L Biodistribution and toxicity of engineered gold nanoparticles: A review of in vitro and in vivo studies. Chem Soc Rev 2011;40(3):1647-1671.

27. Lipka J, Semmler-Behnke M, Sperling RA et al. Biodistribution of PEG-modified gold nanoparticles following intratracheal instillation and intravenous injection. Biomaterials. 2010;31(25):6574-6581.

28. Geng F, Xing JZ, Chen J et al. Pegylated glucose gold nanoparticles for improved in-vivo bio-distribution and enhanced radiotherapy on cervical cancer. J Biomed Nanotechnol. 2014;10(7):1205-1216.

29. Hu Y, Xie J, Tong YW, Wang CH Effect of PEG conformation and particle size on the cellular uptake efficiency of nanoparticles with the HepG2 cells. J Control Release. 2007;118(1):7-17.

30. Walkey CD, Olsen JB, Guo H et al. Nanoparticle size and surface chemistry determine serum protein adsorption and macrophage uptake. J Am Chem Soc. 2012;134(4):2139-2147.

31. Rahme K, Chen L, Hobbs RG et al. PEGylated gold nanoparticles: polymer quantification as a function of PEG lengths and nanoparticle dimensions. RSC Advances. 2013;3(17):6085-6094.

32. Jokerst JV, Lobovkina T, Zare RN et al. Nanoparticle PEGylation for imaging and therapy. Nanomedicine (Lond). 2011;6(4):715-728

33. Degennes PG Polymers at an interface; a simplified view. Advances in Colloid and Interface Science. 1987;27(3-4):189-209.

34. Larson TA, Joshi PP, Sokolov K Preventing protein adsorption and macrophage uptake of gold nanoparticles via a hydrophobic shield. ACS Nano. 2012;6(10):9182-9190.

35. Arnida, Janat-Amsbury MM, Ray A et al. Geometry and surface characteristics of gold nanoparticles influence their biodistribution and uptake by macrophages. Eur J Pharm Biopharm. 2011;77(3):417-423.

36. Gordon AN, Granai CO, Rose PG et al. Phase II study of liposomal doxorubicin in platinum- and paclitaxel-refractory epithelial ovarian cancer. J Clin Oncol. 2000;18(17):3093-3100.

37. Petros RA, DeSimone JM Strategies in the design of nanoparticles for therapeutic applications. Nat Rev Drug Discov. 2010;9(8):615-627.

38. Yang C, Neshatian M, van Prooijen M Cancer nanotechnology: enhanced therapeutic response using peptide-modified gold nanoparticles. $J$ Nanosci Nanotechnol. 2014;14(7):4813-4819.

39. Mieszawska AJ, Mulder WJ, Fayad ZA et al. Multifunctional gold nanoparticles for diagnosis and therapy of disease. Mol Pharm. 2013;10(3):831-847 
40. Nativo P, Prior IA, Brust M Uptake and intracellular fate of surfacemodified gold nanoparticles. ACS Nano. 2008;2(8):1639-1644.

41. Levy R, Shaheen U, Cesbron Y et al. Gold nanoparticles delivery in mammalian live cells: a critical review. Nano Rev 1. 2010

42. Eghtedari M, Liopo AV, Copland JA et al. Engineering of heterofunctional gold nanorods for the in vivo molecular targeting of breast cancer cells. Nano Lett. 2009;9(1):287-291.

43. Liu CJ, Wang $\mathrm{CH}$, Chien $\mathrm{CC}$ et al. Enhanced $\mathrm{x}$-ray irradiation-induced cancer cell damage by gold nanoparticles treated by a new synthesis method of polyethylene glycol modification. Nanotechnology. 2008;19(29):295104.

44. Chithrani BD, Ghazani AA, Chan WC Determining the size and shape dependence of gold nanoparticle uptake into mammalian cells. Nano Lett. 2006;6(4):662-668.
45. Chithrani DB, Jelveh S, Jalali $\mathrm{F}$ et al. Gold nanoparticles as radiation sensitizers in cancer therapy. Radiat Res. 2010;173(6):719-728.

46. Chithrani DB, Chan WC Elucidating the mechanism of cellular uptake and removal of protein-coated gold nanoparticles of different sizes and shapes. Nano Lett. 2007;7(6):1542-1550.

47. Chen W, Zhang J. Using0020nanoparticles to enable simultaneous radiation and photodynamic therapies for cancer treatment. $J$ Nanosci Nanotechnol. 2006;6(4):1159-1166.

48. Cho SH. Estimation of tumor dose enhancement due to gold nanoparticles during typical radiation treatments: a preliminary Monte Carlo Study. Phys Med Biol. 2005;50(15):163-173. 